\title{
Rhizoremediation of fuel oil by Vetiveria zizanioides in association with Kocuria sp. no. MU1 and Micrococcus luteus WN01
}

\author{
Sakunpitchaya Promsing ${ }^{\mathrm{a}, \mathrm{b}}$, Prayad Pokethitiyook ${ }^{\mathrm{a}, \mathrm{b}, *}$, Maleeya Kruatrachue $^{\mathrm{a}}$, Puey Ounjai ${ }^{\mathrm{a}, \mathrm{b}}$, \\ Metha Meetam $^{\mathrm{a}, \mathrm{b}}$, Nuttaphon Onparn ${ }^{\mathrm{a}, \mathrm{b}}$, Acharaporn Kumsopa ${ }^{\mathrm{c}}$ \\ a Department of Biology, Faculty of Science, Mahidol University, Bangkok 10400 Thailand \\ b Center of Excellence on Environmental Health and Toxicology (EHT), Bangkok 10400 Thailand \\ c Faculty of Environment and Resource Studies, Mahidol University, Nakhon Pathom 73170 Thailand
}

${ }^{*}$ Corresponding author, e-mail: prayad.pok@mahidol.ac.th

Received 3 May 2020

Accepted 30 Dec 2020

\begin{abstract}
Pot experiments were conducted to determine the rhizoremediation potential of Vetiveria zizanioides in association with bacteria isolated from the oil-polluted area, in fuel oil degradation. The analysis of fuel oilcontaminated soil from Udonthani Province, Thailand, revealed 23 isolates based on their partial 16S rDNA sequences. Among these, only 6 isolates could grow on fuel oil MSM medium. Fuel oil biodegradability assay was performed with the six isolates and the established oil degrader strain Micrococcus luteus WN01. The results showed that M. luteus WN01 and Kocuria sp. MU01 utilized the fuel oil at maximal percentages (86.06\% and $63.12 \%$, respectively). Hence, they were chosen as inoculated bacteria in fuel oil-contaminated soil planted with vetiver grass, in 5 treatments:control, natural attenuation, rhizoremediation, bioaugmentation, and phytoremediation. The results revealed that plants in association with M. luteus WN01 or Kocuria sp. MU01 showed significant increases in total biomass, shoot height and root length, with higher relative growth rates. A significant decrease (>50\%) in total petroleum hydrocarbon (TPHs) concentration in soil, with the highest percentage of removal (50.25\%), was observed in rhizoremediation with $M$. luteus WN01 after 45 days of treatment. Moderate percentages of removal (37-47\%) were shown in rhizoremediation with Kocuria sp. MU01, bioaugmentation and phytoremediation. Natural attenuation exhibited the lowest percentage of removal (20.8\%). These results suggested that mutual benefits between vetiver grass and bacteria M. luteus WN01 or Kocuria sp. MU01 can enhance the rhizoremediation of petroleum hydrocarbon contaminated soil.
\end{abstract}

KEYWORDS: fuel oil-contaminated soil, oil-degrading bacteria, Vetiveria zizanioides, TPH contaminated soil, Micrococcus luteus WNO1, Kocuria sp. MU01

\section{INTRODUCTION}

Petroleum hydrocarbons (PHCs) are one of the natural resources that play very important roles in our daily life. PHCs in the form of stove oil, lubricants and fuel are used in heating and energy for engines and as fuel for industrial processes. Because of this, fuel oil is very popular due to the fact that it is extremely low priced than other petroleum products. The hydrocarbon residues are quite durable and can stay in the environment for a prolonged period [1]. The discharge of PHC to the environment is often associated with its consumption. Also, the discharge from accidents, such as leaks from pipes or containers, as well as transportation and oil spills from abandoned gas stations can result in its contamination in the environment. Oil spills are considered a serious environmental problem and often have significant, long-term impacts on wildlife and human activities in affected areas, where environmental recovery may take several years [1].

Microbial bioremediation and phytoremediation have been widely investigated for the treatment of PHC contaminated sites. Recent research on the use of biosurfactant-producing Bacillus subtilis SE1 isolated from enriched petroleum-polluted soil in bioremediation of hydrocarbon contaminated environment in Thailand has been reported [2]. For phytoremediation, plants are used to degrade, stabilize and/or remove soil contaminants including organic compounds [3]. In the expansion of the two techniques, a convergence of phytoremediation and microbial bioremediation strategies has led to a more successful approach, namely microbe-assisted phytoremediation or rhizoremediation [3]. 
Rhizoremediation is the use of plants and microbiota associated with roots to remove, contain or render harmless environmental contaminants. It is a cost-effective, low maintenance on-site method for remediating petroleum-contaminated soils [3]. The degradation of PHCs in contaminated soil is the result of complex interactions involving roots, root exudates, rhizosphere soil, and microbes [3]. Sugar and organic acids in plant root exudates are commonly used as carbon and energy sources by soil microbes [4]. The microbial consortia can provide various benefits to plants, including the synthesis of compounds that protect the plants, chelators for plant nutrients and the degradation of contaminants [5].

The successful application of rhizoremediation is largely dependent on several factors, such as the tolerance of plants to PHCs, the high ability of bacteria or microbes to degrade PHCs and the capacity of microbes to efficiently colonize growing roots [6]. Therefore, rhizoremediation can be optimized by using suitable plant-microbe pairs, for example, a combination of plants and oil-degrading bacteria. Several species of bacteria are oil-degrading, such as Bacillus, Micrococcus, Pseudomonas, Kocuria [7,8]. These bacteria are capable of degrading light crude oil, diesel oil and polycyclic aromatic hydrocarbons (PAHs). Microbial degradation can be accomplished by different bacterial species that are both native to the soil and added as effective degrading strains [9].

Plants suitable for rhizoremediation have to be tolerant to petroleum contaminants. Many plant species are sensitive to petroleum contaminants and showed inhibition of plant growth parameters, such as germination, shoot length and biomass [10]. Several plant species, including vetiver grass, tall fescue, sorghum, corn, and alfalfa, are effective in degrading total petroleum hydrocarbons (TPHs) and PAHs [11]. Grasses are generally tolerant to petroleum contaminants and have a fast growth rate with high biomass production. Besides, they have an extensive root system, which provides a large surface area for the colonization of oil-degrading bacteria.

Selection of tolerant plant species local to the area and native species of bacteria isolated from petroleum-contaminated soil should be preferred for effective rhizoremediation. Vetiver grass (Vetiveria zizanioides) has been proved to be an effective and tolerant plant for phytoremediation $[11,12]$. Hence, vetiver grass was chosen in this study to investigate the potential for TPHs remediation from fuel oil-contaminated soil. Vetiver grass has been grown in Thailand for a long time, mainly to prevent soil erosion due to its deep root system. It is promising for the amelioration of the soil and has shown tolerance towards petroleum contaminants [12]. It also has the potential for the removal of PAHs from diesel contaminated soil [11]. Thus, this study aimed to investigate the rhizoremediation of oilpolluted soil using $V$. zizanioides inoculated with oildegrading bacteria isolated from oily sludge. The ability of vetiver grass to grow in oil-contaminated soil was evaluated. Total soil bacteria were also quantified to evaluate the effects of inoculated bacterial stimulation on oil biodegradation.

\section{MATERIALS AND METHODS Soil sample collection}

A fuel oil-contaminated soil sample was collected from a PTT (Petroleum Authority of Thailand ) petrol storage station (under the supervision of PTT Research and Technology Institute), Udonthani Province, Thailand. The physicochemical analyses were performed by the Department of Soil Science, Kasetsart University, Bangkok, Thailand. Soil texture was analyzed using hydrometer method; soil $\mathrm{pH}$ was measured using a $\mathrm{pH}$ meter after mixing soil and deionized water in a ratio of $1: 1 \mathrm{w} / \mathrm{v}$ at room temperature; organic matter $(\mathrm{OM})$ by Walkley-Black titration [13]; and cation exchange capacity (CEC) by ammonium saturation method with $1 \mathrm{~N} \mathrm{NH}_{4} \mathrm{OAc}$, $\mathrm{pH} 7.0$ [14]. The total nitrogen was measured by Kjeldahl digestion; available P by spectrophotometric measurement after extracting with Bray II method [15]; and available $\mathrm{K}$ by atomic absorption spectrophotometry after extracting with $1 \mathrm{~N}$ $\mathrm{NH}_{4} \mathrm{OAc}, \mathrm{pH} 7.0$ [16]. Electroconductivity (EC) was measured by electrical conductivity meter after mixing soil and deionized water in a ratio of $1: 5 \mathrm{w} / \mathrm{v}$ at $25^{\circ} \mathrm{C}$. Table 1 summarizes some of the physicochemical characteristics of the soil. The TPH concentration of soil from the petrol storage station was 20000 ppm.

\section{Isolation and identification of oil-degrading bacteria}

Five grams of the oil-contaminated soil sample was added to $50 \mathrm{ml}$ of Luria-Bertani medium (LB) medium and incubated at $30^{\circ} \mathrm{C}$, at $150 \mathrm{rpm}$ for $24 \mathrm{~h}$ to isolate oil-degrading bacteria. Serially diluted soil samples were spread on LB agar plates and incubated at $30^{\circ} \mathrm{C}$ for $48 \mathrm{~h}$. Colonies with different morphological appearances were selected and purified in nutrient agar medium [17]. Chromosomal DNA of each strain was prepared from a single colony 
Table 1 Some physicochemical characteristics of the oil-contaminated soil sample (from petrol storage station) and the spiked soil.

\begin{tabular}{lccl}
\hline Characteristic & \multicolumn{2}{c}{ Contaminated soil } & Analytical method \\
\cline { 2 - 3 } & Sample & Spiked soil & \\
\hline $\mathrm{pH}$ & 7.1 & 7.2 & $1: 1$ soil/deionized water \\
Organic matter $(\mathrm{g} / \mathrm{kg})$ & 2.40 & 2.32 & Walkley-Black titration \\
Texture & Silk clay & Clay & Hydrometer \\
Cation exchange capacity $(\mathrm{cmol} / \mathrm{kg})$ & 31.40 & 28.20 & Ammonium saturation \\
Total nitrogen $(\mathrm{mg} / \mathrm{kg})$ & 1100 & 980 & Kjeldahl \\
Available phosphorus $(\mathrm{mg} / \mathrm{kg})$ & 40 & 28 & Bray II \\
Available potassium $(\mathrm{mg} / \mathrm{kg})$ & 149 & 162 & AAS \\
Electrical conductivity $(\mathrm{dS} / \mathrm{m})$ & 0.77 & 0.23 & $1: 5$ soil/deionized water \\
Total petroleum hydrocarbon $(\mathrm{ppm})$ & 20,000 & 10,000 & Soxhlet \\
\hline
\end{tabular}

using the QIAamp DNA minikit (Qiagen, Valencia, CA, USA) according to the manufacturer's protocol. The 16S rDNA of bacterial isolates was amplified using the universal primers UFUL (GCCTAACACATGCAAGTCGA) corresponding to nucleotide position 39-58 (forward primer) and URUL (CGTATTACCGCGGCTGCTGG) corresponding to nucleotide position 530-511 (reverse primer). These partial sequences were matched in GenBank using the BLAST tool (blastn) on the NCBI web page (http://blast. ncbi.nlm.nih.gov/Blast.cgi) with at least $97 \%$ similarity.

\section{Screening of potential bacteria for fuel oil utilization}

The 23 identified bacterial isolates were screened for their ability in oil degradation and to determine the most efficient degrader. Each of the bacterial cultures was serially ten-fold diluted with sterile $0.85 \% \mathrm{NaCl}$. After that, $100 \mu \mathrm{l}$ of appropriate dilution, were spread on mineral salt medium (MSM) agar plates supplemented with $1 \%$ fuel oil [17]. The plates were incubated at $30^{\circ} \mathrm{C}$ for $48 \mathrm{~h}$ to observe the colony appearance. Colonies were then counted and total microbial count $/ \mathrm{ml}$ was calculated. The extent of bacterial growth was assessed by visual observation of the medium [18].

\section{Fuel oil biodegradability assay}

Fuel oil biodegradation assays were performed with the bacterial isolates having the ability to degrade oil and the oil degrader Micrococcus luteus WN01 deposited at the Department of Biology, Faculty of Science, Mahidol University, Bangkok, Thailand. $M$. luteus WN01 was previously isolated from the wastewater treatment system at a PTT gas station plant; it could degrade and utilize hydrocarbon as the sole carbon source [19]. The initial inoculation was $1 \mathrm{ml}$ bacterial suspension $\left(\mathrm{OD}_{600}\right.$ about 0.5$)$ in $50 \mathrm{ml}$ of MSM medium prepared with $1 \%$ fuel oil as sole carbon source. The medium was sterilized at $121^{\circ} \mathrm{C}$ for $15 \mathrm{~min}$. The culture was incubated at $30^{\circ} \mathrm{C}, 150 \mathrm{rpm}$ for 7 days. Three replicates were performed for each bacterial isolate. Control without bacterial inoculum was also maintained. After the incubation, the extent of oil utilization was assessed by visual observation of the turbidity of the medium [18]. The level of microbial degradation of the oil was determined by gas chromatography (GC, Agilent Technology 6890 N (USA) equipped with a flame ionization detector (FID) and fused silica capillary column (30 m length; $0.25 \mathrm{~mm}$ i.d.; $0.25 \mathrm{~mm}$ film thickness), according to the US EPA 8015 method [20]. The bacterial strains that displayed high ability in biodegrading fuel oil were identified, and their percentages of removal efficiency were calculated to assess their potential use in the treatments of fuel oil-contaminated soils.

\section{Rhizoremediation experiment Soil and plant preparation}

Uncontaminated soil with no history of TPH contamination, was purchased from Chatuchak Market, Bangkok, Thailand was used for spiked soil. Fuel oil (No. 5) was obtained from the PTT Research and Technology Institute. Fuel oil (1\% w/w; $10000 \mathrm{mg} / \mathrm{kg}$ soil) was mixed thoroughly with acetone $(200 \mathrm{ml} / \mathrm{kg}$ of soil) before adding to the soil. The initial TPHs concentration achieved in spiked soil was $10000 \mathrm{mg} / \mathrm{kg}$ soil. The soil was characterized for physicochemical characteristics (Table 1). Vetiver grass ( $V$. zizanioides) Songkla 3 ecotype was obtained from the vetiver station in Pathum Thani Province, Thailand. Plants were acclimatized under 
Table 2 Treatments and conditions.

\begin{tabular}{lll}
\hline Code & Treatment & Condition \\
\hline T1 & Control & Uncontaminated soil + vetiver grass \\
T2 & Natural attenuation & Contaminated soil \\
T3A & Bioremediation & Contaminated soil + vetiver grass + M. luteus WN01 \\
T3B & Bioremediation & Contaminated soil + vetiver grass + Kocuria sp. no. MU1 \\
T4A & Bioaugmentation & Contaminated soil + M. luteus WN01 \\
T4B & Bioaugmentation & Contaminated soil + Kocuria sp. no. MU1 \\
T5 & Phytoremediation & Contaminated soil + vetiver grass \\
\hline
\end{tabular}

prevailing natural environmental conditions for one week prior to the experiment.

\section{Bacterial preparation}

One $\mathrm{ml}$ of bacterial culture (the identified Kocuria sp. MU01 isolated from oil-contaminated soil or M. luteus WN01) was added to $50 \mathrm{ml}$ of LB media and incubated at $30^{\circ} \mathrm{C}, 150 \mathrm{rpm}$ for $72 \mathrm{~h}$. The cells were harvested at stationary phase and resuspended in the MSM media before being inoculated into the soil by adding the bacterial suspension at $10 \mathrm{ml}$ per $\mathrm{kg}$ of dry soil. The experimental soil was packed into plastic pots $(19 \mathrm{~cm}$ in diameter and $22 \mathrm{~cm}$ in height) at $3 \mathrm{~kg} /$ pot. Each pot contained one plant.

\section{Experimental design}

The experiment was conducted in a greenhouse under prevailing natural environmental conditions with natural sunlight and ambient temperature ranged from 27 to $36^{\circ} \mathrm{C}$. There were 7 treatments (Table 2) and the experimental period was 45 days. Each treatment was performed in triplicate. The water supply was $200 \mathrm{ml}$ of tap water every alternate day. Pots were arranged in a randomized complete experimental block design.

\section{Determination of TPHs}

TPHs were determined by the GC-FID system [20]. Two grams of soil sample were extracted with $10 \mathrm{ml}$ of acetone:hexane $(1: 1, \mathrm{v} / \mathrm{v})$ for 15 min using an ultra-sonicator (BANDELIN SONOREX SUPER RK $156 \mathrm{BH}$, Germany). The supernatant was dried by passing through a layer of anhydrous $\mathrm{Na}_{2} \mathrm{SO}_{4}$. Then the second cycle of extraction started using $10 \mathrm{ml}$ hexane for $15 \mathrm{~min}$. The extract was put under a stream of nitrogen gas until dry; then, $1 \mathrm{ml}$ of $\mathrm{n}$ hexane was added and $1 \mu \mathrm{l}$ was injected into a GC system. The weight of residual TPHs was deter- mined from subtracting the weight of empty vial from the weight of vial containing extracted TPHs. The percentage of degradation was calculated from

$$
\% \text { Degradation }=\frac{\left(\mathrm{TPH}_{\text {initial }}-\mathrm{TPH}_{\mathrm{t}}\right)}{\mathrm{TPH}_{\text {initial }}} \times 100,
$$

where $\mathrm{TPH}_{\text {initial }}$ is initial soil $\mathrm{TPH}$ concentration, $\mathrm{TPH}_{\mathrm{t}}$ is soil TPH concentration at time $t$, and $t$ is $7,15,30$ and 45 (day).

\section{Bacterial plate count}

At each sampling day of the experiment $(0,7,15$, $30,45)$, samples were taken out from the pots and analyzed for viable cell count; and the extent of biodegradation was determined. The bacterial counts were determined with standard dilution plating technique using sterile nutrient agar; and the colony forming units were counted after incubation [21]. One gram of soil samples was mixed with $9 \mathrm{ml}$ of $0.85 \%$ sterile $\mathrm{NaCl}$ solution and shaken vigorously until the mixture was thoroughly mixed. After appropriate serial dilutions, $1 \mathrm{ml}$ each of three dilutions was inoculated on sterile LB agar plates and incubated at $30^{\circ} \mathrm{C}$ for 3 days. The plates containing between 30 and 300 colonies were counted and expressed as a colony-forming unit (cfu)/g dry soil.

\section{Data analysis}

Plant growth was estimated by measuring the stem height, root length and dry biomass. The relative growth rate (RGR) was calculated by dividing the difference in plant weight between the initial and the final fresh weight. The percentage of oil biodegradation was determined by calculating the average of peak height area of each compound on the chromatogram of a biodegraded sample after different experimental periods to the initial sample [21]. 


\section{Statistical analysis}

Data were processed using analysis of variance (ANOVA) in the SPSS-18 statistical software package (SPSS, Inc.). Multiple comparisons of means of experimental parameters of each treatment, including the percentage of TPHs degradation (\%) and counts of bacteria, were made using Tukey's HSD test at $p<0.05$. The interpreted results represented the average of three replicates and were presented as the mean \pm standard error.

\section{RESULTS AND DISCUSSION}

\section{Soil characteristics}

The physical and chemical characteristics of oilcontaminated soil (spiked with TPHs) used in the rhizoremediation experiment are shown in Table 1. The soil $\mathrm{pH}$ was neutral ( $\mathrm{pH}$ 7.2). The soil texture was clay soil with moderate levels of organic matter $(2.32 \mathrm{~g} / \mathrm{kg})$ and the CEC value was $28.20 \mathrm{cmol} / \mathrm{kg}$. In the soil background, the amounts of essential nutrients were relatively high and suitable for plant growth, especially the available phosphorus (28 mg/kg) and potassium (162 mg/kg). The TPHs content in contaminated soil was 10000 ppm soil. From the results, all plants grown in both contaminated soil and uncontaminated soil appeared healthy and there were no abnormalities or discoloration of plant organs. They maintained 100\% survival rate for the whole duration of the experiment (45 days).

\section{Identification of isolates and their fuel oil utilizing potential}

The analysis of fuel oil-contaminated soil from PTT petrol storage station revealed 23 bacterial isolates that were separated into three phyla: Proteobacteria with dominant species (15 isolates); Actinobacteria (2 isolates) including Kocuria sp. MU01 and Kocuria sp. MU02; and Firmicutes (6 isolates). Testing the isolates and $M$. luteus WN01 for their potential to utilize fuel oil as a sole carbon and energy source revealed that six isolates, Exiguobacterium sp., Lysinibacillus sp., Kocuria sp. MU01, Ochrobactrum sp., Alcaligenes sp., and Achromobacter sp. and M. luteus WN01 were able to utilize fuel oil.

\section{Fuel oil biodegradability assay}

The 6 bacterial isolates and M. luteus WN01 were assayed for fuel oil biodegradation. M. luteus and Kocuria sp. MU01 showed the highest percentage of TPHs degradation (86.08\% and $63.12 \%$ degradation, respectively), followed by Achromobacter sp. (56.02\%). The moderate degradation percentage was observed in Exiguobacterium sp. (45.55\%) and Alcaligenes sp. (40.02\%). The lowest degradation percentage was found in Ochrobactrum sp. (23.46\%), Lysinibacillus sp. (22.33\%) and control (natural attenuation, 18.66\%). Hence, M. luteus and Kocuria sp. MU01 were chosen for the rhizoremediation experiment. Similar bacteria were also isolated from PHC contaminated soil and water, for example: Achromobacter, Micrococcus, Kocuria, Bacillus [22]. The dominant species in the present study belonged to the genus Bacillus and Proteobacteria. The different capacities of the isolates in degrading fuel oil may be due to their different hydrocarbon degradation enzyme systems, i.e., some bacteria can degrade hydrocarbon more rapidly than others [7].

\section{Rhizoremediation}

The results of plant growth performance in the rhizoremediation study are shown in Table 3. Different growth parameters, including dry biomass, shoot height, root length, and relative growth rate (RGR), were measured at day zero and 45 days after exposure. In general, the dry biomass, shoot height and root length of $V$. zizanioides in all vegetated treatments (T1, T3A, T3B, T5) significantly increased with the exposure time $(p \leqslant 0.05)$. In addition, all vegetated treatments did not show any significant difference in dry biomass production $(p>0.05)$. However, the dry biomass of plants grown in contaminated soil with bacterial inoculation exhibited an increase of $52.2 \%$ (M. luteus WN01, T3A) and 38\% (Kocuria sp. MU01, T3B) when compared with control (T1) (Table 4). Vetiver grass grown in oil-contaminated soil alone showed a 29.4\% decrease in dry biomass when compared with control (Table 4). The maximum total dry weight was found in T3A (M. luteus WN01, $5.13 \mathrm{~g} / \mathrm{plant})$ followed by T3B (Kocuria sp. MU01, $4.65 \mathrm{~g} / \mathrm{plant}$ ), T1 (control, $3.37 \mathrm{~g} /$ plant), and T5 (no bacteria, $2.38 \mathrm{~g} /$ plant) (Table 3 ).

The difference between the shoot height of vetiver grass grown in oil-contaminated soil (T5, $60 \mathrm{~cm}$ ) and uncontaminated soil (T1, 74.5 cm) was significant $(p \leqslant 0.05)$ (Table 3$)$. The maximal shoot height was found in T3A $(94.5 \mathrm{~cm})$, followed by T3B $(77.8 \mathrm{~cm})$ and $\mathrm{T} 1(74.5 \mathrm{~cm})$, while the minimal shoot height was shown in T5 $(60 \mathrm{~cm})$. Bacterial inoculation into contaminated soil positively affects the shoot height of vetiver grass. No significant differences in shoot height were observed among T1 (control), T3A (M. luteus WN01) and T3B (Kocuria 
Table 3 Dry biomass production (DW, g/plant), shoot height $(\mathrm{cm})$, root length $(\mathrm{cm})$ and relative growth rate (RGR) of $V$. zizanioides grown in various soil treatments for 45 days.

\begin{tabular}{lccllr}
\hline Treatment code & Day & Dry biomass & Shoot height & Root length & RGR \\
\hline T1 & 0 & $1.53 \pm 0.05^{\mathrm{a}, \mathrm{A}}$ & $20.00 \pm 0.00^{\mathrm{a}, \mathrm{A}}$ & $10.00 \pm 0.00^{\mathrm{a}, \mathrm{A}}$ & $0.000 \pm 0.000$ \\
& 45 & $3.37 \pm 0.61^{\mathrm{a}, \mathrm{B}}$ & $74.50 \pm 0.70^{\mathrm{b}, \mathrm{B}}$ & $19.00 \pm 1.41^{\mathrm{a}, \mathrm{B}}$ & $0.023 \pm 0.003$ \\
\hline T3A & 0 & $1.46 \pm 0.06^{\mathrm{a}, \mathrm{A}}$ & $20.00 \pm 0.00^{\mathrm{a}, \mathrm{A}}$ & $10.00 \pm 0.00^{\mathrm{a}, \mathrm{A}}$ & $0.000 \pm 0.000$ \\
& 45 & $5.13 \pm 1.92^{\mathrm{a}, \mathrm{B}}$ & $94.50 \pm 14.14^{\mathrm{b}, \mathrm{B}}$ & $23.50 \pm 7.77^{\mathrm{a}, \mathrm{B}}$ & $0.035 \pm 0.009$ \\
\hline T3B & 0 & $1.47 \pm 0.11^{\mathrm{a}, \mathrm{A}}$ & $20.00 \pm 0.00^{\mathrm{a}, \mathrm{A}}$ & $10.00 \pm 0.00^{\mathrm{a}, \mathrm{A}}$ & $0.000 \pm 0.000$ \\
& 45 & $4.65 \pm 1.11^{\mathrm{a}, \mathrm{B}}$ & $77.75 \pm 3.88^{\mathrm{b}, \mathrm{B}}$ & $18.00 \pm 7.07^{\mathrm{a}, \mathrm{B}}$ & $0.033 \pm 0.005$ \\
\hline T5 & 0 & $1.52 \pm 0.15^{\mathrm{a}, \mathrm{A}}$ & $20.00 \pm 0.00^{\mathrm{a}, \mathrm{A}}$ & $10.00 \pm 0.00^{\mathrm{a}, \mathrm{A}}$ & $0.000 \pm 0.000$ \\
& 45 & $2.38 \pm 1.31^{\mathrm{a}, \mathrm{A}}$ & $60.00 \pm 4.24^{\mathrm{a}, \mathrm{B}}$ & $19.50 \pm 0.70^{\mathrm{a}, \mathrm{B}}$ & $0.017 \pm 0.011$ \\
\hline
\end{tabular}

Values are mean \pm SE $(n=3)$. Those followed by the same letter did not differ; small letters showed differences between treatments; capital letters showed differences between exposure time at $p<0.05$ according to the Tukey's HSD test.

Table 4 Range of influence of bacterial inoculation on changes in plant growth parameters in various soil treatments.

\begin{tabular}{lccc}
\hline \multirow{2}{*}{$\begin{array}{l}\text { Treatment } \\
\text { code }\end{array}$} & \multicolumn{3}{c}{ Range of variation (\% increase) } \\
\cline { 2 - 4 } & Dry biomass & Shoot height & Root length \\
\hline T1 & 100.0 & 100.0 & 100.0 \\
T3A & 52.2 & 26.9 & 23.7 \\
T3B & 38.0 & 4.4 & -5.3 \\
T5 & -29.4 & -19.5 & 2.6 \\
\hline
\end{tabular}

sp. MU01). In addition, the bacteria did not show any significant influence in root length among all treatments $(p>0.05)$. The increases of $26.9 \%$ in shoot height and $23.7 \%$ in root length were observed with $M$. luteus WN01 when compared with control (Table 4).

When the RGR values of all treatments were compared, the highest RGR values were shown in treatments with bacterial inoculation (0.0330.035), followed by those of control (0.023) and treatment without bacteria (0.017) (Table 3). Vetiver grass is a high-biomass plant with a long massive, finely complex structured root system. It is capable of withstanding extreme harsh environmental conditions such as temperature, salinity, heavy metal, and hydrocarbon contamination [12]. Moreover, vetiver grass showed their potential in removing various environmental contaminants from both soil and water $[23,24]$. In the present study, $V$. zizanioides showed a promising behavior in degrading fuel oil-contaminated soil (10000 mg/kg). The successful growth of vetiver grass showed the over time increases in dry biomass, shoot height and root length in all treatments (with or without bacterial inoculation). However, Nisa et al [11] reported the adverse effect of diesel contamination on the growth of $V$. zizanioides, which was slightly suppressed with a decrease in biomass. Considerable decrease of plant biomass, as well as shoot height and root length by the presence of PHCs, was found in several cases, including wheat, ryegrass, corn, fescue, sorghum, and common flax [25]. Plant growth inhibition can be caused by toxic compounds in PHCs, especially low molecular weight hydrocarbons. Hydrocarbons can also alter soil properties because of their hydrophobicity, which may result in a reduction in water and nutrient availability and plant growth [10, 26].

Bacterial inoculated treatments showed significant increases in growth parameters when compared with treatments without inoculation. These results were supported by Omokeyeke et al [27], who reported that the interactions between plants and rhizosphere bacteria in oil-contaminated soil caused an increase in plant biomass. In general, soil conditions at contaminated sites are very low in nutrients. The presence of rhizosphere bacteria can improve plant growth due to their plant growth-promoting activities, such as the production of phytohormones, ACC (1-amino-cyclo-propane-1carboxylic acid) deaminase, siderophore production, and phosphorus solubilization [28].

\section{Biodegradation of TPHs}

The residual concentrations of TPHs remaining in soil and percentages of TPHs removal in different treatments are shown in Table 5 and Fig. 1, respectively. TPHs concentrations decreased in all treatments after 45 days of the experiment. The statistical analysis revealed that the TPHs removal 
Table 5 Residual TPHs concentrations in contaminated soils of different treatments.

\begin{tabular}{|c|c|c|c|c|c|}
\hline \multirow{2}{*}{$\begin{array}{l}\text { Treatment } \\
\text { code }\end{array}$} & \multicolumn{5}{|c|}{ TPHs concentration in soil $(\mathrm{mg} / \mathrm{kg})^{\dagger}$} \\
\hline & 0 days ${ }^{*}$ & 7 days* & 15 days* & 30 days" & 45 days* \\
\hline T2 & $9241.05 \pm 97.68^{\mathrm{a}, \mathrm{A}}$ & $8314.00 \pm 730.79^{\mathrm{a}, \mathrm{AB}}$ & $8398.33 \pm 307.70^{\mathrm{a}, \mathrm{AB}}$ & $7483.75 \pm 135.26^{\mathrm{a}, \mathrm{B}}$ & $7356.68 \pm 271.75^{\mathrm{a}, \mathrm{B}}$ \\
\hline T3A & $9801.19 \pm 79.20^{\mathrm{a}, \mathrm{A}}$ & $5725.33 \pm 71.97^{\mathrm{b}, \mathrm{B}}$ & $5508.98 \pm 56.37^{\mathrm{b}, \mathrm{C}}$ & $6806.79 \pm 219.64^{\mathrm{ab}, \mathrm{B}}$ & $4878.26 \pm 935.92^{c, C}$ \\
\hline T3B & $9060.15 \pm 275.65^{\mathrm{a}, \mathrm{A}}$ & $7883.58 \pm 259.14^{\mathrm{a}, \mathrm{B}}$ & $7557.89 \pm 134.64^{\mathrm{ab}, \mathrm{B}}$ & $6164.52 \pm 476.79^{\mathrm{bc}, \mathrm{C}}$ & $6145.60 \pm 172.24^{\mathrm{ab}, \mathrm{c}}$ \\
\hline $\mathrm{T} 4 \mathrm{~A}$ & $9602.26 \pm 147.35^{\mathrm{a}, \mathrm{A}}$ & $7056.04 \pm 38.77^{\mathrm{ab}, \mathrm{BC}}$ & $6077.68 \pm 192.22^{\mathrm{bc}, \mathrm{B}}$ & $7766.30 \pm 307.53^{a, C}$ & $6411.15 \pm 708.03^{\mathrm{ab}, \mathrm{c}}$ \\
\hline T4B & $9744.11 \pm 753.55^{\mathrm{a}, \mathrm{A}}$ & $8999.78 \pm 572.61^{\mathrm{a}, \mathrm{A}}$ & $6838.41 \pm 51.97^{\mathrm{ab}, \mathrm{A}}$ & $6519.87 \pm 382.11^{\mathrm{b}, \mathrm{A}}$ & $6161.94 \pm 569.87^{\mathrm{ab}, \mathrm{A}}$ \\
\hline T5 & $10043.85 \pm 981.22^{\mathrm{a}, \mathrm{A}}$ & $6721.23 \pm 735.94^{\mathrm{b}, \mathrm{C}}$ & $7924.45 \pm 24.67^{\mathrm{a}, \mathrm{B}}$ & $6985.66 \pm 33.32^{\mathrm{ab}, \mathrm{BC}}$ & $5892.32 \pm 539.55^{\mathrm{ab}, \mathrm{c}}$ \\
\hline
\end{tabular}

" Days after treatment. ${ }^{\dagger}$ Values are mean \pm SE $(n=3)$. Those followed by the same letter did not differ; small letters showed differences between treatments; capital letters showed differences between exposure time at $p<0.05$ according to the Tukey's HSD test.

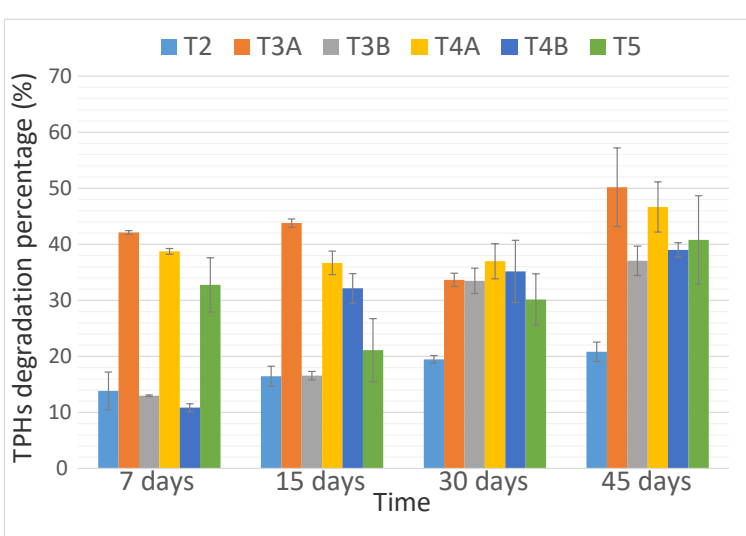

Fig. 1 TPHs degradation efficiency in contaminated soil with different treatments.

could be divided into 3 levels, i.e. highest, moderate and lowest removal percentages. The highest percentage of TPHs removal (50.2\%), with the lowest residual TPHs concentration $(4878 \mathrm{mg} / \mathrm{kg}$ ), was shown in rhizoremediation treatment with vetiver and M. luteus WN01 (T3A). The moderate removal percentages (37.1-46.7\%) were shown in phytoremediation (T5, 40.8\%), bioaugmentation (T4A, 46.4\%; T4B, 39\%) and rhizoremediation with Kocuria sp. MU01 (T3B, 37.1\%). These treatments exhibited medium concentrations of residual TPHs $(5892-6411 \mathrm{mg} / \mathrm{kg})$. The lowest removal TPHs percentage (20.8\%), with the highest TPHs residual concentration $(7356.7 \mathrm{mg} / \mathrm{kg})$, was found in natural attenuation (T2).

A rapid increase in the degradation (around $40 \%$ ) was observed at the initial period of remediation after 7 days for T3A (vetiver grass + M. luteus WN01) and T4A (M. luteus WN01 alone) (Fig. 1). Treatments with the inoculation of Kocuria sp. MU01 showed a slight delay in degradation, i.e., 15 days for T4B (Kocuria sp. MU01 alone) and
30 days for T3B (vetiver grass + Kocuria sp. MU01). In T2 (natural attenuation) and T5 (phytoremediation) treatments, there was a gradual increase in TPHs degradation from day 7 to day $30(30-32 \%)$ and became higher (41\%) on day 45 (Fig. 1).

According to this study, TPH removal efficiency, as well as plant growth, was improved by the addition of oil-degrading bacteria. Several reports showed that the rhizosphere bacterial inoculation could enhance plant growth and remediate contaminants. Inoculation of maize (Zea mays) with Bacillus subtilis can successfully enhance phytoremediation of petroleum hydrocarbons [29]. Afzal et al [30] found that the maximum hydrocarbon degradation (83\%) and toxicity reduction (84\%) were observed in ryegrass inoculated with Burkholderia phytofirmans PsJN. Buffalo grass (Brachiaria mutica) and Kallar grass (Leptochlo afusca) showed the potential to remediate soil contaminated with crude oil (78\%) when combined with a consortium of Acinetobacter sp. strain BRSI56 and Pseudomonas aeruginosa strain BRRI54 [31]. Enterobacter cloacae VW4\&CAL2 induced the growth of tall fescue (Festuca arundinacea) and enhanced TPH degradation [32]. Gordonia sp. S2RP-17 inoculation could enhance remediation efficiency as well as promote the growth of maize in diesel-contaminated soil [33].

As previously stated, the rhizoremediation treatments with inoculation of M. luteus WNO1 or Kocuria sp. MU01 showed a high percentage of TPH removal (37-50\%) after 45 days. Species of Kocuria and Micrococcus have been consistently isolated from oil-polluted soil and implicated in PHC degradation. Micrococcus was reported to degrade low molecular weight PAHs, diesel oil and TPHs [7]. Similar to our study, Jampasri et al [19] also reported that rhizoremediation of fuel oil and $\mathrm{Pb}$ co-contaminated soil using Chromolaena odorata 


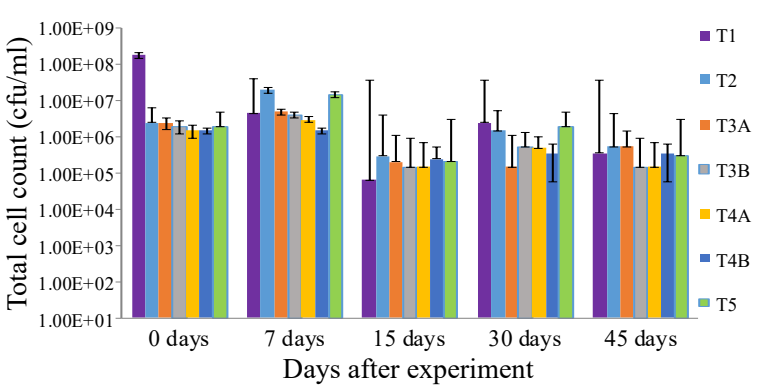

Fig. 2 Comparison of total bacterial population over a 45-day experiment. The result was expressed as colony forming unit (CFU).

inoculated with $M$. luteus WN01 showed a 52\% reduction of TPHs. Several species of Kocuria were able to degrade PAHs, diesel oil and crude oil $[8,34]$. El Mahdi et al [35] also confirmed that Kocuria sp. can utilize crude oil as the sole carbon source and has a high ability to degrade crude oil up to $70 \%$ in 28 days. Kocuria sediminis DDK6 had the ability to degrade $\mathrm{C}_{14}-\mathrm{C}_{19}$ compounds in diesel oil [8]. Ahmed et al [34] also demonstrated that $K$. flava and $K$. rosea showed the ability to degrade naphthalene, phenanthrene, fluoranthene, and crude oil. Several studies reported that the production of biosurfactants by Kocuria enhanced bacterial oil degradation [36]. Biosurfactant derived from Kocuria sp. emulsified more than 50\% of the crude oil. Sarafin et al [37] also highlighted that $K$. marina produced biosurfactants reflecting its efficiency in oil degradation.

In this study, the addition of M. luteus WN01 and Kocuria sp. MU01 to the contaminated soil showed the rapid reduction of TPH during the first 2 weeks. This result confirms the report of Haritash [38], who also found the degradation of low molecular weight PAHs by two bacterial species, M. luteus and Kocuria rosea, after 15 days. The maximal degradation was observed for naphthalene (68.7\%) followed by phenanthrene (62.9\%), fluoranthene (61.4\%) and pyrene (61.3\%). Bento et al [39] also reported that the number of oil-degrading bacteria increased in the first two weeks. These suggested that the lower chain alkane $\left(\mathrm{C}_{14}-\mathrm{C}_{18}\right)$ was degraded rapidly within 15 days due to their labile properties; so they are easy to degrade by bacteria to obtain carbon source for growth and activities. In theory, the rates of hydrocarbon degradation are in the following order: linear alkanes $>$ branched alkanes $>$ aromatic hydrocarbons $>$ polycyclic hydrocarbons. In addition, the rapid TPH degradation during the first two weeks might be due to a greater bacterial population and sufficient nutrient availability for the degrading microbes.

\section{Total bacterial population}

The results revealed that from the initial day to the end of the experiment, when compared between planted soils with or without bacteria (T1, T3A, T3B, and T5) and unplanted soils (T2, T4A, T4B), the planted soil treatments showed higher total bacterial population than the unplanted. The total bacterial population showed a rapid rise until day 7 in all treatments (Fig. 2). The highest number of bacteria $\left(1.8 \times 10^{8} \mathrm{cfu} / \mathrm{ml}\right)$ was observed in $\mathrm{T} 1$ at the initial day, followed by T3A $\left(2.5-5 \times 10^{6} \mathrm{cfu} / \mathrm{ml}\right)$ and T3B $\left(2-4 \times 10^{6} \mathrm{cfu} / \mathrm{ml}\right)$. A rapid initial increase in the microbial population in all treatments indicated the abundance of carbon sources in oilcontaminated soil. Gradually, the microbial population tended to slightly decline and became stable until the end of the experiment with the reduction in residual alkane concentration. The lack of carbon sources due to degradation with time could be related to the decrease in the microbial population in the soil. The results of the overall microbial population showed that the plant and the fuel oil could promote the growth of microorganisms in contaminated soil. After 45 days, the number of the colonies was in the range of $10^{-5}-10^{-8} \mathrm{cfu} / \mathrm{ml}$ for planted soil.

In this study, the total bacterial populations in the planted soils were higher than those in the unplanted, demonstrating the bacterial effects of rhizosphere-bacteria interactions [27, 28]. The growth of hydrocarbon-degrading bacteria can be stimulated because plant root exudates contain compounds structurally similar to various PHCs [28]. More nutrients in the soil can be accounted for more microbial population. It has been shown that plants may contribute to the dissipation of PAHs by an increase in microbial numbers [29-31].

Mezzari et al [40] reported that the increase in bacterial population correlated with the presence of grasses, indicating that rhizosphere stimulated bacterial growth which ultimately enhanced hydrocarbon removal. The microbial population present in the root zone or rhizosphere can degrade hydrocarbons or make them more bioavailable. The removal of these compounds becomes more feasible through the metabolic transformation processes of plant-microbe interaction [4]. 


\section{CONCLUSION}

The present study was designed to determine the rhizoremediation potential of Vetiveria zizanioides in association with bacteria isolated from the oilpolluted area, in fuel oil degradation. Based on the results of the present work, $V$. zizanioides possess the ability to grow well and withstand the fuel oil concentration upto $10000 \mathrm{mg} / \mathrm{kg}$ soil. It is interesting to mention that the inoculation of bacteria increased plant growth as well as hydrocarbon degradation. The results showed that $M$. luteus WN01 and Kocuria sp. MU01 utilized the fuel oil at maximal percentage of removal $(>50 \%)$. Therefore, the utilization of vetiver grass and specially the interaction of vetiver grass and oil degrading bacteria suggests an alternative strategy for effective rhizoremediation of soils contaminated with petroleum hydrocarbon. Furthermore, a lab-scale experimental system for rhizoremediation is widely performed due to low cost. It does not only reduce the period of plant growth and length of exposure, but also reduces both the space needed for experiments and variability due to other environmental factors. However, lab scale testing results still need to be confirmed by field performance trials.

Acknowledgements: This work received a major financial support from the Petroleum Authority of Thailand Public Company Limited, Bangkok, Thailand. This research work was also funded by a grant from the Center of Excellence on Environmental Health and Toxicology (EHT), Ministry of Higher Education, Science, Research and Innovation, Thailand.

\section{REFERENCES}

1. Kuppusamy S, Maddela NR, Megharaj M, Venkateswarlu K (2020) An overview of total petroleum hydrocarbons. In: Total Petroleum Hydrocarbons, Springer, Switzerland, pp 1-27.

2. Nimrat $S$, Lookchan $S$, Boonthai $T$, Vuthiphandchai V (2020) Isolation, optimisation and gasoline biodegradation by lipopeptide-producing Bacillus subtilis SE1. ScienceAsia 46, 195-205.

3. Gerhardt KE, Huang XD, Glick BR, Greenberg BM (2009) Phytoremediation and rhizoremediation of organic soil contaminants: potential and challenges. Plant Sci 176, 20-30.

4. Leigh MB, Fletcher JS, Fu X, Schmitz FJ (2002) Root turnover: an important source of microbial substrates in rhizosphere remediation of recalcitrant contaminants. Environ Sci Technol 36, 1579-1583.

5. Dams RI, Paton GI, Killham K (2007) Rhizoremediation of pentachlorophenol by Sphingobium chlorophenolicum ATCC 39723. Chemosphere 68, 864-870.
6. Lugtenberg BJ, Dekkers L, Bloemberg GV (2001) Molecular determinants of rhizosphere colonization by Pseudomonas. Annu Rev Phytopathol 39, 461-490.

7. Ali A, Abdul W (2019) Biodegradation and phytotoxicity of crude oil hydrocarbons in an agricultural soil. Chilean Jar 79, 266-277.

8. Khalifa AY (2017) Degradation of diesel-oil by a newly isolated Kocuria sediminis DDK6. Afr J Microbiol Res 11, 400-407.

9. Tang JC, Wang RG, Niu XW, Wang M, Chu HR, Zhou QX (2010) Characterisation of the rhizoremediation of petroleum-contaminated soil: effect of different influencing factors. Biogeosciences 7, 3961-3969.

10. Bossert I, Bartha R (1985) Plant growth in soils with a history of oily sludge disposal. Soil Sci 140, 75-77.

11. Nisa WU, Rashid A, Aziz NB, Mahmood T, Islam K, Kazmi SK, Raziq M (2015) Potential of vetiver (Vetiveria zizanioides L.) grass in removing selected PAHs from diesel contaminated soil. Pak $J$ Bot 47, 291-296.

12. Srivastava J, Kayastha S, Jamil S, Srivastava V (2008) Environmental perspectives of Vetiveria zizanioides (L.) Nash. Acta Physiol Plant 30, 413-417.

13. Walkley A, Black IA (1947) Determination of organic matter in the soil by chromic acid digestion. Soil Sci 63, 251-264.

14. Chapman HD (1965) Cation-exchange capacity. In: Norman AG (Ed) Methods of Soil Analysis: Part 2 Chemical and Microbiological Properties, 9.2, American Society of Agronomy Inc., Madison, pp 891-901.

15. Bray RH, Kurtz LT (1945) Determination of total, organic, and available forms of phosphorus in soils. Soil Sci 59, 39-46.

16. Jackson ML (1958) Soil Chemical Analysis, PrenticeHall, Inc., Englewood Cliffs, NJ, USA.

17. Disi AZ, Jaoua S, Thani DA, Meer SA, Zouari N (2017) Considering the specific impact of harsh conditions and oil weathering on diversity, adaptation, and activity of hydrocarbon-degrading bacteria in strategies of bioremediation of harsh oily-polluted soils. BioMed Res Int 2017, 1-11.

18. Okpokwasili GC, Okorie BB (1988) Biodeterioration potentials of microorganisms isolated from car engine lubricating oil. Tribol Int 21, 215-220.

19. Jampasri K, Pokethitiyook P, Kruatrachue M, Ounjai P, Kumsopa A (2016) Phytoremediation of fuel oil and lead co-contaminated soil by Chromolaena odorata in association with Micrococcus luteus. Int J Phytoremediation 18, 994-1001.

20. USEPA (1996) Method 8015: Non-halogenated Organics using GC/FID, US Environmental Protection Agency, USA.

21. Chang LK, Ibrahim D, Omar IC (2011) A laboratory scale bioremediation of Tapis crude oil contaminated soil by bioaugmentation of Acinetobacter baumannii T30C. Afr J Microbiol Res 5, 2609-2615. 
22. Unimke AA, Bassey IU, Mmuoegbulam AO, Ikat HN (2017) Microbial community profiling of spent-oil contaminated soil in Odukpani, Nigeria. Asian J Environ Ecol 3, 1-7.

23. Kiamarsi Z, Kafi M, Soleimani M, Nezami A, Lutts S (2020) Conjunction of Vetiveria zizanioides L. and oil-degrading bacteria as a promising technique for remediation of crude oil-contaminated soils. $J$ Clean Prod 253, 1-11.

24. Janadeleh H, Hosseini Alhashemi A, Nabavi SMB (2016) Investigation on concentration of elements in wetland sediments and aquatic plants. GJ Environ Sci Manag 2, 87-93.

25. Shirdam R, Zand A, Bidhendi G, Mehrdadi N (2008) Phytoremediation of hydrocarbon-contaminated soils with emphasis on the effect of petroleum hydrocarbons on the growth of plant species. Phytoprotection 89, 21-29.

26. Merkl N, Schultze-Kraft R, Infante C (2004) Phytoremediation in the tropics. The effect of crude oil on the growth of tropical plants. Bioremediation $J \mathbf{8}$, 177-184.

27. Omokeyeke O, Sikoki FD, Nwachukwu EO (2013) Phytoremediation potential of an aquatic weed, Eichornia crassipes, in crude oil contaminated sites. In: Proceedings of the Annual International Conference Life Sciences \& Engineering Chapter 3, Syiah Kuala University, Banda Aceh, Indonesia, pp 125-130.

28. Naveed M, Mitter B, Yousaf S, Pastar M, Afzal M, Sessitsch A (2014) The endophyte Enterobacter sp. FD17: a maize growth enhancer selected based on rigorous testing of plant beneficial traits and colonization characteristics. Biol Fertil Soils 50, 249-262.

29. Asghar HN, Rafique HM, Khan MY, Zahir ZA (2017) Phytoremediation of light crude oil by maize (Zea mays L.) bio-augmented with plant growth promoting bacteria. Int $J$ Soil Sediment Contam 26, 749-763.

30. Afzal M, Yousaf S, Reichenauer TG, Sessitsch A (2012) The inoculation method affects colonization and performance of bacterial inoculant strains in the phytoremediation of soil contaminated with diesel oil. Int J Phytoremediation 14, 35-47.

31. Fatima K, Imran A, Amin I, Khan QM, Afzal M
(2016) Plant species affect colonization patterns and metabolic activity of associated endophytes during phytoremediation of crude oil-contaminated soil. Environ Sci Pollut Res 23, 6188-6196.

32. Huang XD, El-Alawi Y, Gurska J, Glick BR, Greenberg BM (2005) A multi-process phytoremediation system for decontamination of persistent total petroleum hydrocarbons (TPHs) from soils. Microchem $J$ 81, 139-147.

33. Hong SH, Ryu H, Kim J, Cho KS (2011) Rhizoremediation of diesel-contaminated soil using the plant growth-promoting rhizobacterium Gordonia sp. S2RP-17. Biodegradation 22, 593-601.

34. Ahmed RZ, Ahmed N, Gadd GM (2010) Isolation of two Kocuria species capable of growing on various polycyclic aromatic hydrocarbons. Afr J Biotechnol 9, 3611-3617.

35. El-Mahdi AM, Aziz HA, El-Gendy NS, Nassar H (2015) Performance of isolated Kocuria sp. SAR1 in light crude oil biodegradation. $J$ Bioremed Biodeg 6, 1-6.

36. Matvyeyeva OL, Aliieva OR (2014) Microbial biosurfactants role in oil products biodegradation. Int $J$ Environ Bioremediat Biodegrad 2, 69-74.

37. Sarafin Y, Donio MBS, Velmurugan S, Michaelbabu M, Citarasu T (2014) Kocuria marina BS-15 a biosurfactant producing halophilic bacteria isolated from solar salt works in India. Saudi J Biol Sci 21, 511-519.

38. Haritash AK, Kaushik CP (2016) Degradation of low molecular weight polycyclic aromatic hydrocarbons by microorganisms isolated from contaminated soil. Int $J$ Environ Sci 6, 646-656.

39. Bento FM, Camargo FA, Okeke BC, Frankenberger WT (2005) Comparative bioremediation of soils contaminated with diesel oil by natural attenuation, biostimulation and bioaugmentation. Bioresour Technol 96, 1049-1055.

40. Mezzari MP, Zimermann DMH, Corseuil HX, Nogueira AV (2011) Potential of grasses and rhizosphere bacteria for bioremediation of dieselcontaminated soils. Rev Bras Ciênc Solo 35, 2227-2236. 